\title{
Effect of Text in Contemporary Architectural Formation (Kinetic Architecture as a Case Study)
}

\author{
Ibrahim Jawad Kadhim Al-Yousif ${ }^{1}$ Shaimaa M. Hamza Al-Hayabi ${ }^{2}$ \\ ${ }^{I}$ Department of Architectural Engineering, University of Technology \\ ${ }^{2}$ Department of Architectural Engineering, College of Engineering, Al-Mustansiriyah University \\ ibrahimc4_11@yahoo.com, shaimaamh2002@gmail.com
}

\begin{abstract}
Architecture is a language, and this means that we understand each phrase in a language or text in it, which is built in our architecture. Texts have richness and complexity, and the openness of the architectural text ahead of the act of interpretation, lead to social interaction.
\end{abstract}

Where the text reads in terms of reference, structure, and philosophical vision, and its variables, and comparing it with kinetic architecture as a product of the relationship between human behavior and kinetic waves which have considered a real revolution in architectural thought, where has changed the path of the architecture, where it changed the path of the architecture that has seen from the perspective of persistence and physical and formal stability on the ground to the perspective of movement, dynamism and the formal and positional changes of the building. The role of the process (time) has a significant impact on the kinetic architecture through which the movement can be, and it is an essential element of the movement's principles and conditions in its contemporary architectural formations.

So the research aims to statement of the relationship of the text of the concepts of the text to the concepts of the system of human actions in being and its content becoming and process, against the system of architectural acts in the components of the text (reference structure, and philosophical vision), and reflect this relationship on kinetic architecture as a contemporary architectural formation to know its relationship with the text and its components.
Paper History:( Received:25-11-2018 , Accepted:7-12019)

\section{Introduction}

The architectural text represents a basis for the production of architectural formations, and requires knowledge of the importance of the text and its elements for the purpose of reading all the different architectural texts. It translating them into their basic components and reading them according to their references, structure and philosophical vision.

\section{First: The System of Human Action}

The system of human action consists of the concepts of being, becoming and process, when being is the physical presence that occupies a place in space, consciously or beyond human consciousness. The process is the time (movement) associated with the material is inextricably linked, and as the link between the material and the time, the movement is the form of physical presence[1]. However, this understanding remains incomplete if we do not consider the becoming. There is a third dimension that results from the inextricably linked between the material and the time, which is the development and transformation from "being " in the first case, to "becoming" in a second case. If presence is confined to being and the process without development and becoming to prove presence in one form doesn't diversity, the "becoming" results from a change in the being of the thing and affects the nature of its physical (fig. 1). We conclude after all this that we are facing the following situations of these three levels [2]:

Keywords: Text, Reference, Structure, Philosophical Vision, Contemporary Formation.

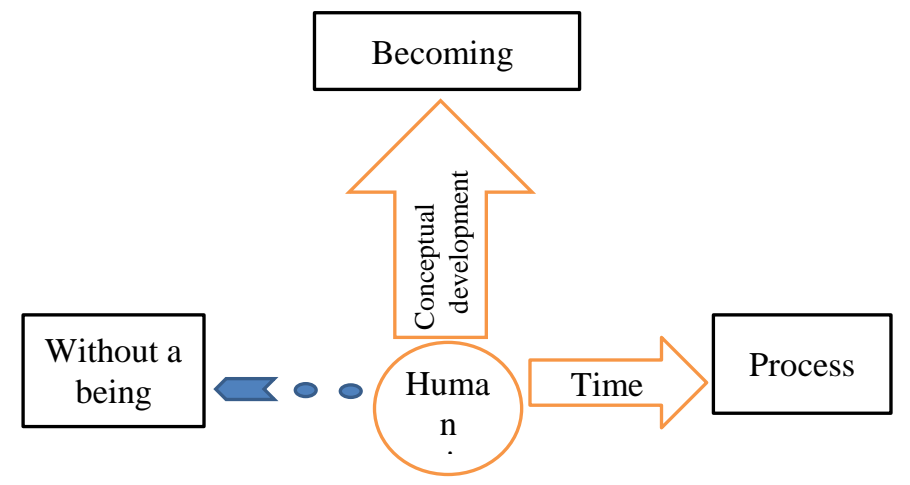

Figure 1: Relationship of Human Action in the Being, Becoming and Process [2] 
1) Production and time without transformation: a static presence, without a teleological error, and if there is time has a meaning of another, free of transformation and change and free from development and selection. All these are located on the axis of becoming in the

2) transformation. Thus, the presence of the product in its being and the time achieved in it, as a flat form represents the presence of the product in all its components, while the transformations in it represent a development and transformation in the presence of production (fig. 2)

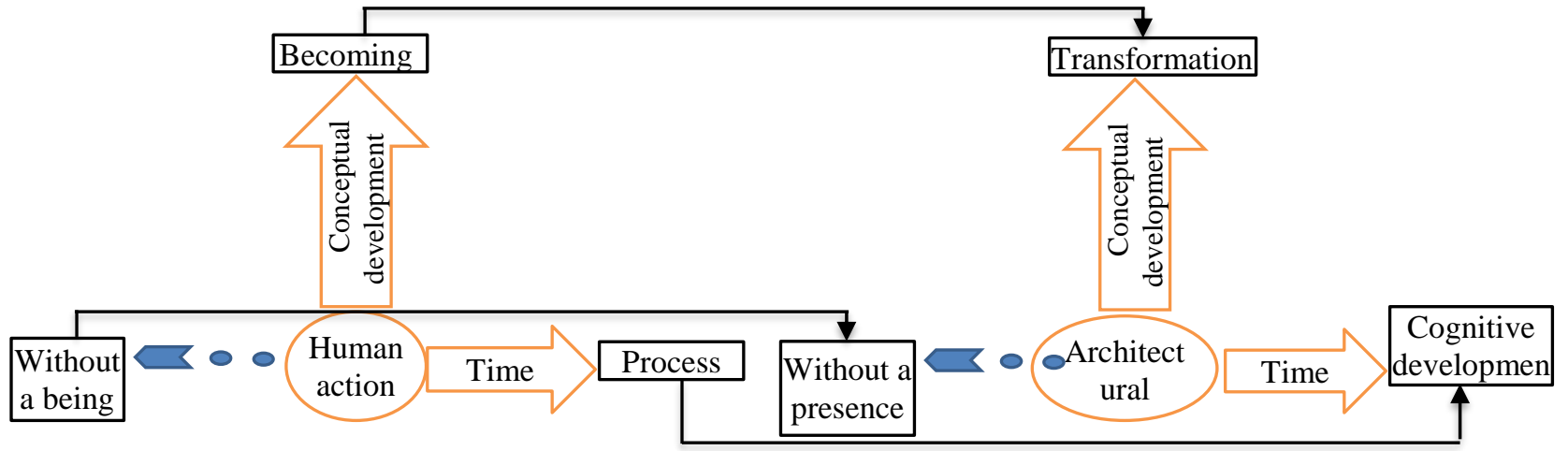

Figure 2: Approach Human Action to Architectural Action.

3) However, when the product has a presence of multiple transformations, it is lost to the impact of time and its movement, that is, the transformation from the presence of production to its multiple image without movement and time. When it is dealing with the presence of product and transformations in it, it gives perceptions of the products of no time, so that the integration of the material component of the multiple transformations without impact to time, meaning that there is no movement or time in it, until:

- Time loses its influence and known meaning.

- The product in its forms and laws have fixed in its composition doesn't change nor develop, and this may be missing its presence.

4) The presence of product and transformation without a time: It means the transition from "being" to "becoming" without movement and time, if we take the axis of being and becoming, we have a level of no "process", in which an being is integrated into its becoming without a process, which it has without movement and time, and time loses its influence and known meaning, to become presence forms and laws fixed don't change nor develop. This doesn't presence except in light. The light isn't subject to change and transformer which is either present or nonpresent, and in its present only one form. Every object that moves at the speed of light becomes and it continues to its final destination. If there is a being and a becoming without a process leads to the presence - stability of presence...... phenomenon - stability of phenomenon.
5) Time, transformation and teleological without presence: At this level, the law of conflict of contrasts shows the same thing, it is both itself and not itself at the same time, and this is the law of negation and negation of negation behind the teleological.

6) In architecture, the law of negation and negation of negation is the basic law that lies in the teleological, located in the same architectural movements from the moment of appearance, which represents the moment of negation of what preceded it and the emergence of a new architectural trend is negation of negation and so on.

From this we conclude the correlation between human actions (being - becoming - process). The process that is the movement of time. It remains in the space if it doesn't have a moving object to become its effect into a "becoming" which is not formed without time (process). From (fig. 3), we explain the following:

1) The human action produced by the interaction of the subjective and objective, which is characterized by change, and its changing situations are indicative of three dimensions of time (past, present and future), where the essence of presence is temporal, to be resolved in a place that reflects that interaction. The mental presence can be defined in the temporal movement in the subjectivity through realized meanings, as opposed to the external presence in the objectivity of the place through the forms generated and the text units contained therein.

2) Formation is a text unit and is read through reference, structure and philosophical vision. 


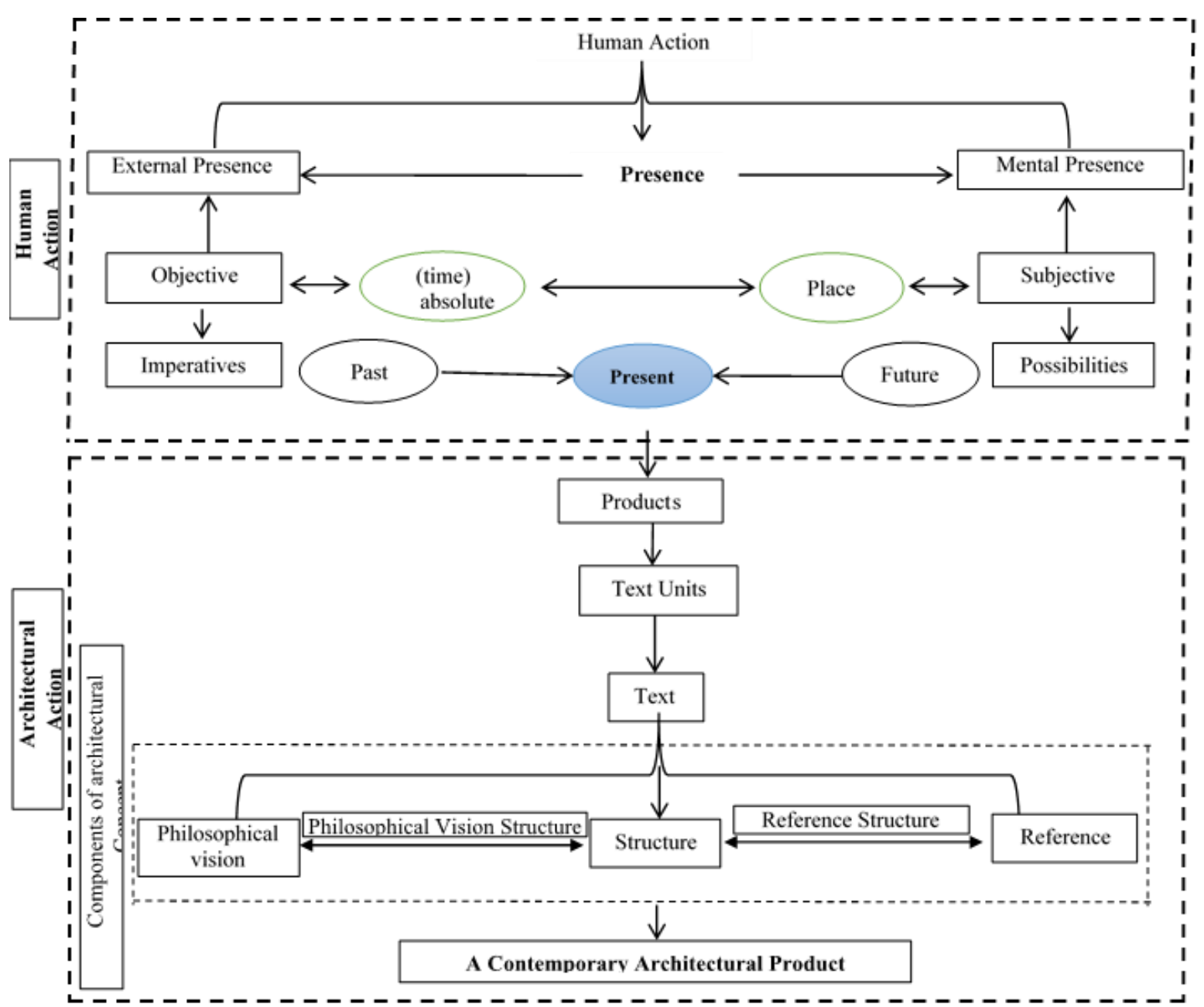

Figure 3: Relationship between the Human Action and the Text. Researchers

\section{Second: The System of Architectural Action}

The system of architectural action includes the concept of text, philosophical vision and structure, which are related to architectural formation.

\subsection{Concept of Text}

Text is a self-contained written language system that is composed of vocabulary it can be called text units linked to each other by multiple relationships, which can be dealt with in many ways, including "Disassembly and reconstruction"[3]. The concept of the text corresponds to the concept of the architectural concept, which is the assumption of the designer that he wants to achieve the goal in the project, which is represents the way of arranging different elements, abstract concepts and observations or perceptions, as well as sensory and aesthetic criteria [4].

The text consists of two levels:

1) Physical level: It is the physical essence which is the actual image and presence, and that we can impose the length, width and depth. It includes the architectural formation, the product of architecture, and the product of the formation.
2) Essentiality level: It is the hidden aspect of the text which reflects the idea of the concept and is read according to the cultural and cognitive dimension of the society. It includes formation architecture, production architecture, and production formation.

\subsubsection{Text Components}

The text consists of three coordinates (reference, philosophical vision and structure), each of which contributes to the reversal of a perception within the reading process.

1) Reference: The reference is the basis in the text, as it contributes to the codification of the set of concepts and social, behavioral and psychological relationships, and all the values and vocabulary from which the knowledge background of the text was formed [5].

The references are two categories (tangible) and (intangible). The tangible references include: the field of architecture, including local and global urban models, previous classical patterns, and previous works of architecture itself; and outside the field of architecture: including natural, industrial and artistic references, as well as mores, traditions, legends, tales and others. 
Intellectual references and theories of science and behavior (functional) as a type of references (from outside the field of architecture) [6].

The characteristics have invested in the reference are either essentiality (mentally) characteristics, that are perceived by mind, or physical characteristics (formally) and perceived to be visually, or combined (formally or mentally), its perception is aesthetic, through them, the produce can be evaluated by reference (fig. 4).

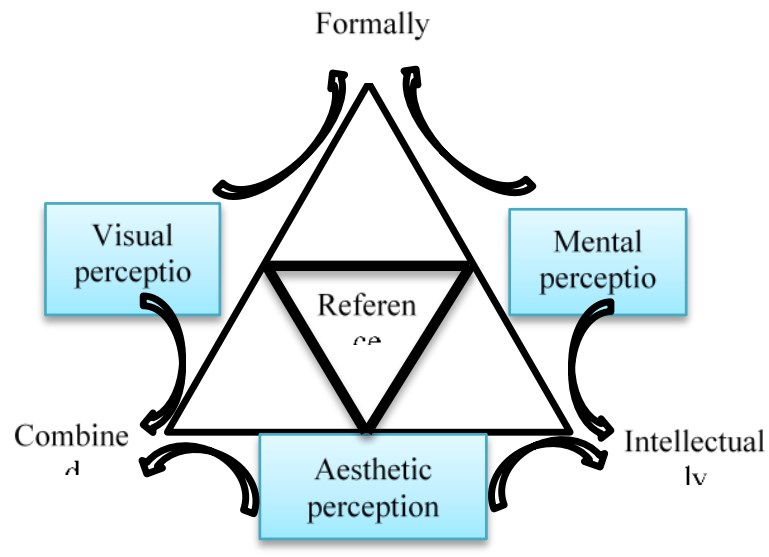

Figure 4: Relation of Reference to Mental and Formal Characteristics. Researchers

2) Philosophical Vision: It's the second coordinate of the text, it's relationship with the critical reading process. The architectural text can be expressed through its content and vision, which reflects a creative vision.

The theoretical foundations of modern architecture have formed through the commitment of the functional school, which has become the top of the schools that adopted the pragmatic approach, that puts the law of utility and interest in the top of the list of design priorities translated into the functional architecture and the efficiency of its performance and the shape is later produce a quote (the form follows the function). The architects of deconstruction have been characterized by views that indicate the incomplete text and its association with the meaning, but it is a fabric of differences and effects that refer to something outside the text, leading to the destabilization of traditional relations between form (text) and its meaning [7].

Figure (5) shows that there are many sources that have been expressed in the field of vision, and that the design theories have been emphasized, as well as many design strategies that reflect how the philosophical vision is linked with the accredited references, add to the emergence of many of the formulas for the realization of philosophical vision as mechanisms of achievement.

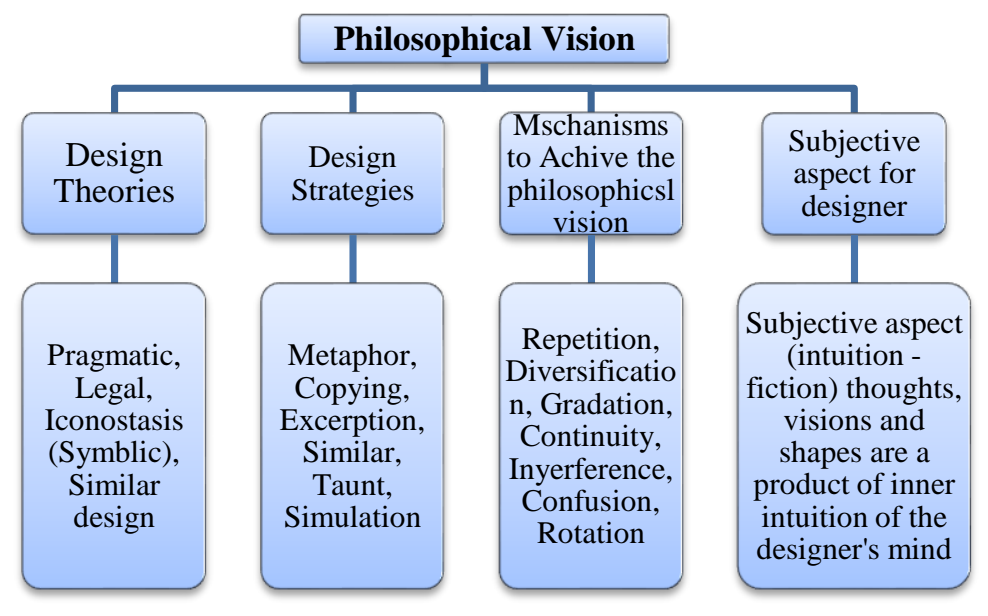

Figure 5: The Relationship Between the Architectural Text and the Philosophical Vision. Researchers 
That philosophical vision is related to:

- Identity: that represents the zeitgeist and deliberation.

- Belongingness: that represents the zeitgeist and suitability.

- Comprehensiveness: that represents the suitability and deliberation.

Each of which is linked to relationships between them, and it's converging with the movement of human action in presence and then the multiple transformations over time, which has acquired a comprehensive character in its reference and achieved belonging in the product and knowledge of an identity, which gives an open movement beginning with the identity and ending. The philosophical vision represented in (fig. 6):

- Deliberative: It is through the philosophy of comprehensiveness identity.

- Suitability: It is through the comprehensiveness of belonging.

- Zeitgeist: it is through the philosophy of belonging to a certain identity.

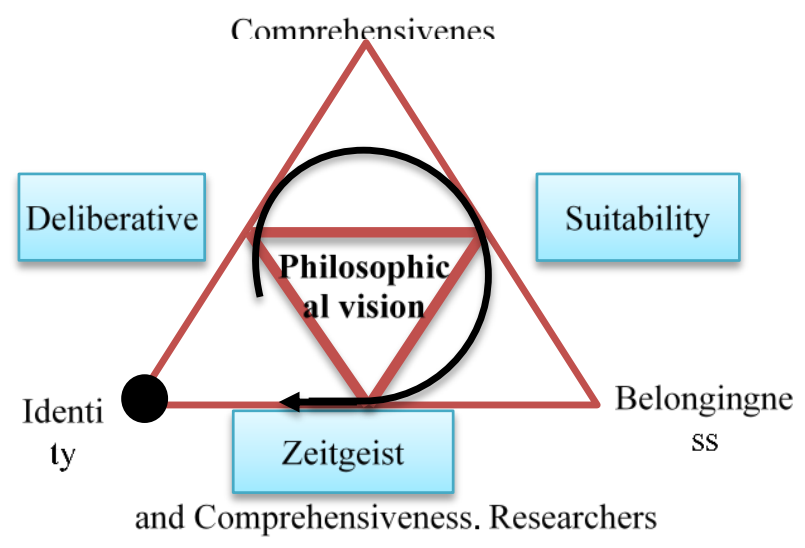

3) Structure: The most dynamic axis in the text concept is the structure in terms of its performance in the reversal of knowledge reference concepts. Figure (7) shows the features, identity and components of the structure, and the approach to the concepts of philosophical visions of identity, belongingness and comprehensiveness.

The figure (7) shows the following:

- The features of the structure are multi-meanings, flexibility and contextual compatibility.

- The identity of the structure has been revealed through the new unfamiliar elements and the arrival of the identity to the truth through the subjective and spirit of the architecture, in addition to compatibility with the era to reach understanding of the essence leading to the produce of the local identity is clear.

- therefore, it can be said that the structure has characteristics (comprehensiveness, transformations, and subjective-regularity), the characteristics of that product must be deepened in terms of the comprehensiveness of the form and content, and to derive the nature of the transformations resulting from the elements of that product, which don't affect the nature of its rules of procedure. This is done by emphasizing that the structure includes (elements or parts, relationships that link those parts within the whole, and finally to the laws of the format or the comprehensiveness system that includes all and parts) (fig. 8).

The figure shows that depending on the context of a function, there is a distinct flexibility in the appearance and meaning of the shapes to new content and a new context different from a precedent.

The context animation cycle is therefore repeated through the requirements of the text in the need for new meanings consistent with the multiple variables and influencing on context through human needs versus external conditions affecting. Thus, multiple images are achieved into context consistent with new insights of text.

In summary of the foregoing:

- Reading the three levels (reference, philosophical vision, structure) by collecting them, it is achieving integration among them and thus achieving the improvement and development of the architectural structure in a modern way through the production of architectural texts characterized by originality and contemporary that achieve communication and interconnection with place and time in forms and architectural formations characterized by modernity, power of meaning and the possibility to perceive it aesthetically, mentally and visually.

- The process of the approach between the three variables (reference, philosophical vision, structure) shows their correlation and interaction with each 
other, and their impact on the architectural product in order to achieve comprehensiveness in the meaning and form in accordance with the function of the building in order to meet the requirements of aesthetic perception and zeitgeist.

- The text is of great importance in the architectural products, which is the basis to achive the human need through the formation of the vocabulary and components of the product, with a series of transformations and processes over time to reach an architectural belonging to the place, that takes into account the social and environmental foundations of society in a spirit appropriate to the time..

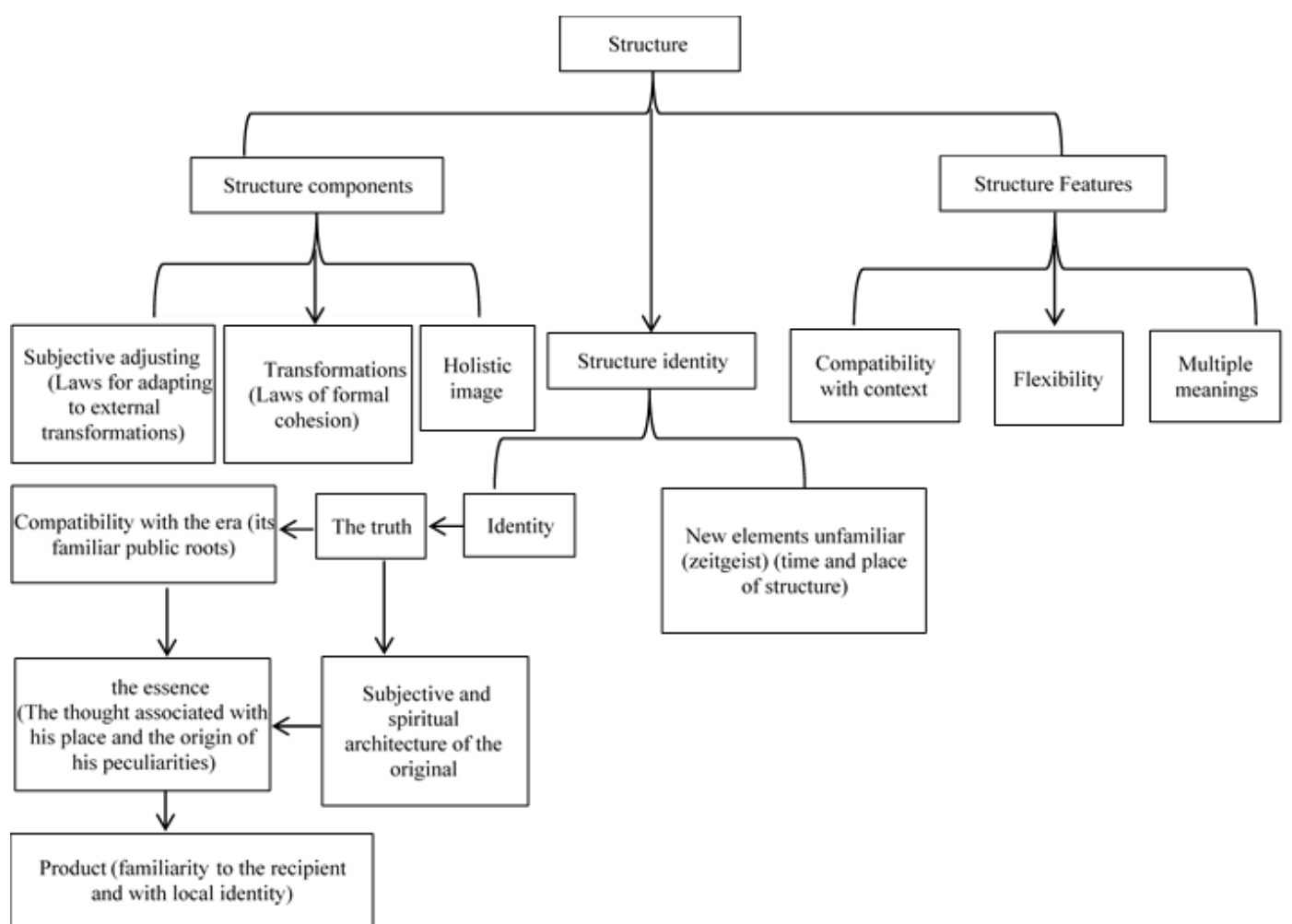

Figure 7: Components, Features and Identity of the Structure. Researchers

\section{2-2 Relationship of Human Action Components to} Architecture, Text and Formation

There are multiple relationships between these words as follows (Figure 9):
1) The relationship of "being" to "architecture": architecture is a civilized phenomenon characterized by the multiplicity and complexity of its elements and functions.

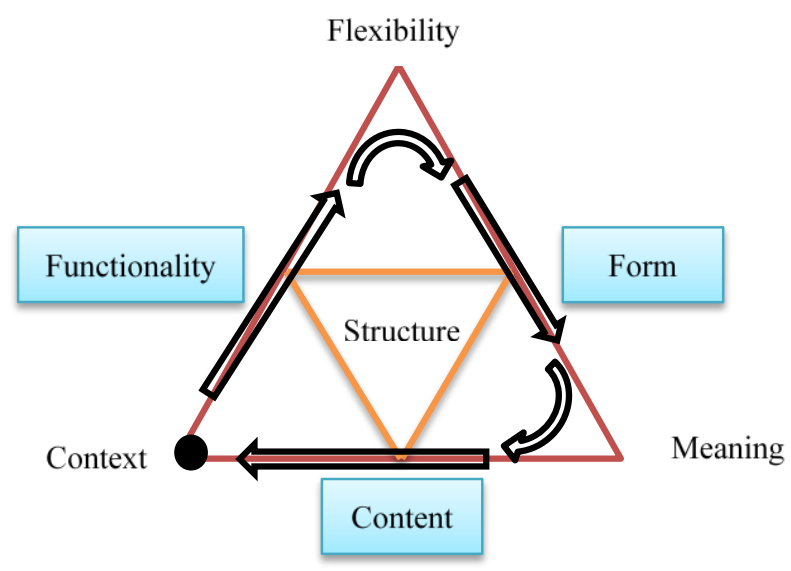

Figure 8: Relationship Structure in the Meaning, Context and Flexibility. Researchers 
It has being since ancient times, and worked as a lot of philosophers, thus differed views on the nature of the architecture from one field to another, and differed within the field itself in spacetime, according to prevailing intellectual trends and principles. The architecture seeks to adopt the golden ratio as a sacred ratio in measuring the aesthetic of human product, and its presence in the production of the architects of the twentieth century [8].

2) The relationship of the "process" to the "text": The change in non-living organisms, including the phenomenon of architecture is limited to a change in form, that is, the formal change in architecture over time is a representative of the axis of the "process". The transformation of Muslim architecture towards the mosque is associated with the same believer, or an Islamic architecture, which is the architecture of the earth in Islam, which is represented by architectural forms and patterns that have emerged for religious and cultural purposes in the lands under Muslim rule.

However, the transition to modernity has been done by need or industrialization and its impact on human production, as the emergence of new materials from the needs of man [9].

3) The relationship of the "becoming" to "formation": based on a change in concepts through the cumulative image and development image. The idea of adopting forms depending on the functional need or required for a spatial community may impose the use of forms or their conclusion to forms that accommodate the required activities of the component. It is later the distinctive characteristic of their architecture and not others. For example, the use of the hexagonal form of the people of the Israelites, and the fact of the matter, doesn't belong to them, but they have the most formal and functional part of the belief of others. This is related to the need for an expression resulting from the mental image or the intellectual vision created within the mind, which consists of creative efforts. It generates an architectural concept that is characterized by the comprehensiveness of the words of the design and selection in one concept that represents them and is directed to influence others from society and social, economic or environmental attitudes when forming concepts [10].

Figure (9) shows the following:

1) Convergence of the three basic concepts of the following: the philosophical vision of zeitgeist, the structure of the function, and reference of aesthetic perception.

2) The architectural texts are based on a trilogy (being, becoming and process). These work on the production of architectural formations in accordance with the different intellectual and philosophical trends and in accordance with the place and time. The existence of the transformation action within the processes of architectural formation gives the variety of the product and thus various architectural products with different texts. The reading of the three basic concepts is done according to the importance of the physical and moral, matter and time, movement and time aspect, and levels of transformation between the axes of the coordinates of these aspects to achieve the development and transformation of architectural products.

3) The basic variables of the texts of (reference, philosophical vision and structure) must achieve the product of architecture characterized by originality, innovation, excellence and creativity. These variables work at several levels:

- The first level works to enrich the meaning with a comprehensive view through the adoption of formal references.

- The second level aims to achieve identity and belonging through the philosophical vision of architectural production and to integrate its structure with the context in a flexible manner by adopting intellectual and composite references.

- The third level represents the overlap of the first and second levels. The philosophical vision of the text and the product must achieve the zeitgeist in a suitable manner with the place and time. It can be deliberative by the designer and the recipient. The structure of the text and the product must reflect the function of the product, reflecting its meaning clearly and explicitly, and expressing the true content of the form of product. The references to the text and the product must be capable of visual, mental and aesthetic perception and reflect the essence and the content of the reference.

Here is the need to study the text and the human action to its applications in the architecture and choice of Kinetic architecture and justify it.

\section{Third: Kinetic Architecture}

Kinetic architecture, sometimes called interactive architecture or dynamic architecture, is a product of contemporary developments and technologies that the world has witnessed over the past few decades. This type of architectural design has been based on human behavior due to the current technical and temporal changes and how it changes the life path of man, and make it shorten time and effort on some of the kinetic factors in buildings inhabited by man and exercise its functions in life. Kinetic architecture is a product of the relationship between human behavior and direct and indirect kinetic waves, with the aim of knowing how kinetic dynamics affect human work functions [11].

\section{3-1 The Concept of Kinetic Architecture}

The term (Kinetic architecture) refers to the concept of the design of buildings produced by the movement, that if the building achieves a balance between humanitarian needs and the conditions of the external environment, it lowers the demand for material resources.

The term kinetic architecture as a form might interact with a set of pressures that create a balance and might not 
be stable for time. This does not mean that some structures and buildings might not be fixed, it is necessary to provide some degree of stability and historical continuity [12].

It is the architecture that has been allocated for transition and change of formality and that functions better, and has been considered one of the necessities of the design for its ability to absorb change, and its movement is classified into various types [13]:

- Movement overlapping with composition.
- Movement compound in building blocks.

- A separate movement into internal and external parts, functional, expressive and symbolic.

The functional factor is a very important factor in the formation of a flexible building depending on its ability to absorb multiple functions by changing shape and space by interacting with the structure. Such buildings are today known as open buildings, which open to the world [14]. 


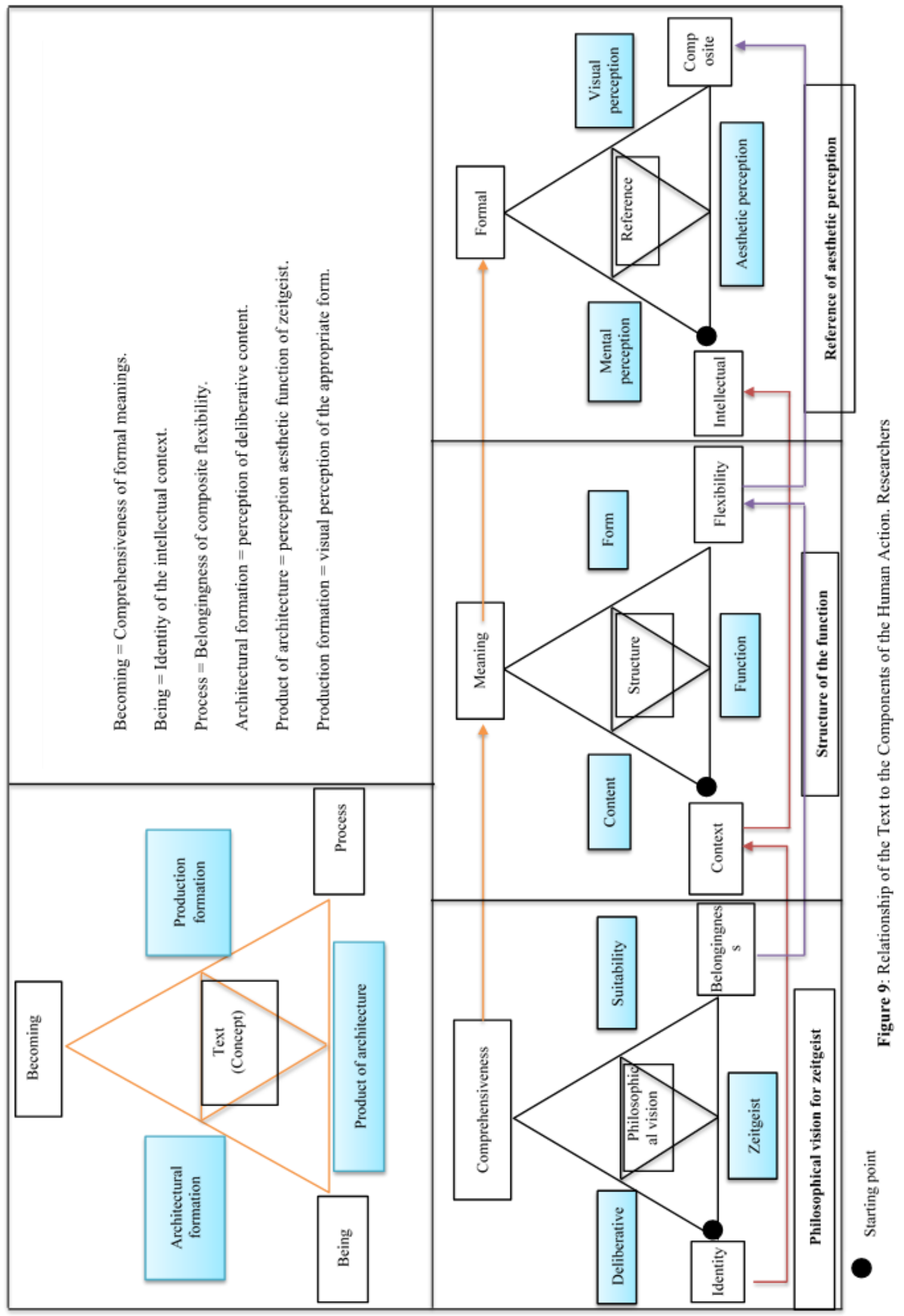




\subsection{Types of Kinetic Architecture}

Kinetic architecture is divided into two types according to its principle, which depends on the rotation of the building around a specific axis of rotation [15]:

- Kinetic architecture has connected to movement in which the whole building is connected to a single motion.

- The kinetic architecture is a separate movement in which each part of the building, such as the floor, is separated by its movement from the other parts.

Figure (10) shows that kinetic architecture arises from the overlap of a set of variables that are formed by the need, the individual and contemporary techniques, which are interconnected to be the products of Kinetic architecture, since the relationship of the individual to the need is achieved through the balance and historical stability of the references and intellectual and philosophical concepts of the individual and society . The need for kinetic waves in architecture has achieved by using contemporary techniques of comfort and aesthetic for the architectural product in a dynamic manner. Therefore, it requires the individual to absorb the formal, functional and intellectual change of architecture towards an architecture that suits contemporary individual needs.

\section{3-3 Principles of Kinetic Architecture}

One of the most important principles of motor architecture is [16]:

1) Time: Time is a fundamental element of the movement's principles and conditions, as the movement takes place over a specified period, that is, the movement is in the presence of time. Just as we have defined the place, size, or body in three dimensions (length, width, and height), in new concepts we add time as a fourth dimension, as important as other dimensions.

2) Physics and balance: Physics has always been associated with the movement and analyzed it, to provide us with an understanding of the mechanics of the movement and ways to modify them. Perhaps the most important branch of physics is mechanics and its dynamic branch, which meant studying objects under the influence of forces on them. Dynamic has analyzed the movement and its section for types: one-dimensional, twodimensional, rotational, cyclic, vibration and oscillatory movement.

3) Speed and acceleration: the movement takes place within a certain speed, without any change between two different situations in an accelerated or even slow movement.

4) Form and the repetitive sequence: For the body to be moving, it must be moved according to a certain formula. It is either simple or complex (such as the bodies that change in form during movement), we get distinct kinetic forms in complexity, and can incorporate two or more moving elements.

5) Mass and weight: Mass and weight have a clear and strong effect on movement. Moving and stopping large mass is more difficult than relatively small. Today, the mass of the element must be considered in both design and implementation phases. It is relatively new to architects, this effect is even more important when a movable building is intended, or part of it is designed to be movable.

6) Complexity and scale: the combination of individual movements in a kinetic chain increases the geometric complexity of the movements by adding two or more individual movements in the kinetic chain that increases the complexity of the overall movement considerably.

7) Interaction: To interact different meanings in different sciences, interactive architecture is a powerful guide to the challenge of creating dynamic spaces and to prove that things can perform a combination of practical and humanitarian functions together. These complex physical interactions occur through the creative integration of embedded computing (intelligence) with a tangible physical counterpart (movement).

\section{3-4 Elements of Movement Construction}

Elements are used in movement construction according to three main goals including idea, objective, purpose and component according to [17]:

1) The mechanical representation aspect of the movement: that is, when the forms are derived from nature or according to the innovations of the designer. The mechanical representative may be real or model or close to renewal.

2) The functional aspect of the movement: is that the movement design communicates the message and purpose of the building designed to meet the practical need of it by users or serve its purpose.

3) Expressionist or aesthetic aspect: The building aims to attract attention through its movement and change its form.

These three aspects are applied across three strategies are [18]:

- Thought strategies and kinetic design.

- Technical strategies for movement construction.

- Strategies for the impact of kinetic beauty on the recipient.

Figure (10) shows the concept of kinetic architecture according to the components of the text (reference, philosophical vision, structure). It has shown through three levels: 


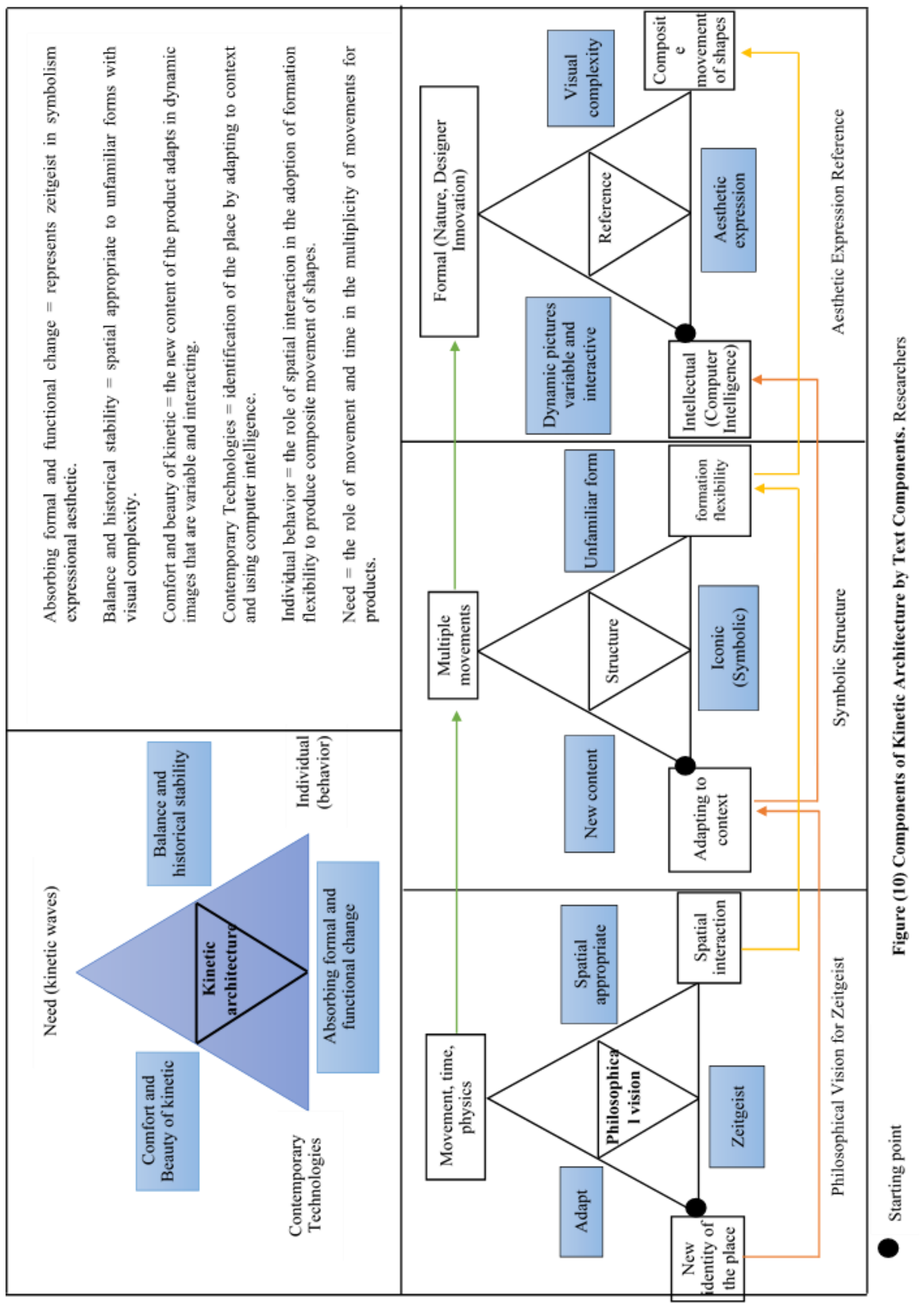


1) The first level of the concept of kinetic architecture in the field of its philosophical vision is that it adopts the physical sciences as a vision of time and movement which is the intellectual and philosophical basis of kinetic architecture, and this is reflected in the structure of kinetic architecture through the multiplicity of movements constituent of the architectural composition of most of its products architecture. Most architectural composition rely on inspiration from natural references that are characterized by movement and flow.

2) Second level: kinetic architecture gives the place a new identity through the spatial interaction of the building adapting it to the surrounding context, by adopting the flexible formation of the building and its consistency with the context, and show the design of the building by creating a virtual environment using computer and modern softwarw in the output of architectural products through composite movements of shape to form production professionally.

3) Third level: It shows that the philosophical vision of kinetic architecture simulates the needs of the zeitgeist in a way, that adapts to the spatial environment of its products. The function of kinetic architecture is the symbolic functional that reflects the zeitgeist through the new content of architecture with its buildings and products in unfamiliar forms. Thus, the emergence of dynamic images that are variable and interacting with the context and the recipient in visually complex forms expressing the aesthetic value of kinetic architecture.

\section{Conclusion}

1) The importance of the text and its translation into known components helps us the recipient to understand and assimilate them to be part of the architectural culture of the architects and society.

2) Kinetic architecture produces contemporary architectural composition based on movement (time) as a base element of the composition to give a new spatial identity that works to achieve the spatial interaction of the building in a modern spirit.

3) The structure of kinetic architecture is characterized by flexibility of composition, multiplicity of movements and adaptation to the context to give form to new, unfamiliar content.

4) Kinetic architecture depends on the formation of the product on the nature to create unfamiliar forms to produce dynamic and complex images that are aesthetical by adopting modern technologies (computer and modern software).

\section{Recommendations}

1) The applicability of the components of the text to any modern architectural trend to know its structural, philosophical and reference components, and the possibility of translating it to the recipient in a simplified form in order to be understood can be absorbed mentally and visually.

2) The introduction of a single course has entitled "Text in Architectural Composition " to be given in the second stage, to increase the ability of students to analyze the architectural texts of buildings at different periods, and the possibility of preparing special texts for each student analyzed according to the components of the text.

\section{References}

[1] Heidegger, Martin, Being and Time, translated by Fethi Meskini, Dar Alkitab Aljadeed for publication, 2012, p. 56.

[2] Abdul Hussein, Adel Moneem, The Impact of a Possibility in the Communicative Architectural Product, Ph.D. Thesis, Architectural. Eng. Dept., Technology University, Baghdad, 2015, p. 20-23

[3] Al.Dahwi, Suha Hassan Abdullah, Text Authority in Architectural Academic Criticism, Ph.D. thesis, Architectural Eng. Dep., University of Technology, Iraq, 2007, p.90.

[4] Al Bakari, Imad M., Concepts Architecture For Architectural Students, AL Rafdain Engineering Journal, volume 15 , issue 4,2007 , p. 84.

[5] Al.Dahwi, op cit, p. 119.

[6] Al.Dahwi, ibid, p. 122.

[7] Ali, Bilal Samir, Dynamics in Contemporary Architecture Text, Master thesis, Department of Architectural Engineering، University of Technology, 2010, p. 9.

[8] Al-Yousif, Ibrahim Jawad, Our Architecture and the Architecture of the other, Dar Al-Walaa for Printing and Publishing, First Edition, Baghdad, Iraq, 2017, p. 37.

[9] Al-Yousif, ibid, p. 66.

[10] Al-Yousif, Ibrahim Jawad, So I read architecture. The Road of an Architecture against an Architecture, Dar AlWalaa for Printing and Publishing, First Edition, Baghdad, 2018, pp. 33-34.

[11] Azzam, Munir Anwar, Kinetic Architecture, The Architectural Magazine Twenty-Two, Issue 54, 2017, pp. 1011.

[12] Azzam, ibid, p. 82.

[13] Kster، Helmut, Dynamic Day Light Architecture, Basic Systems Project, Germany, 2010, p. 5.

[14] Franz, Hans, Dynamic of Machinery Theory and Applications, Springer, Germany, 2011, p. 10.

[15] Randl, Chad, Revolving Architecture - A History of Building That Rotate, Swivel ‘ N Y، 2008, p. 11.

[16] Carlos، Antonio, Dynamic Reconfigurable Architectures and Transparent Optimization Techniques" Springer Science، London، UK, 2010.

[17] Almajedi, Basim Hasan \& Altaee, Mariam, Moving Architecture the Impact of Position Movement of Architecture on the Recipient, Iraqi Journal of Architectural, University of Technology, vol. 28, No. $1 \&$ 2, 2014, p. 60.

[18] Almajedi, ibid, p. 59 